\title{
O transporte e a consolidação de um campus regional no interior do nordeste
}

\author{
Leonardo Herszon Meira ${ }^{1}$, Maurício Oliveira de Andrade², Maria Leonor Alves Maia ${ }^{3}$ e Anísio Brasileiro 4
}

\begin{abstract}
Resumo: A política de interiorização das Instituições Federais de Ensino Superior ocorrida nos últimos 10 anos no Brasil possibilitou a abertura de 2 novos campi da Universidade Federal de Pernambuco em municípios do interior do Estado. Observa-se, no entanto, que essas estruturas foram instaladas em municípios que ofertam, de forma precária, serviços de transporte urbano e regional, impactando no acesso dos usuários a essas estruturas e afetando o desempenho acadêmico dos estudantes. Este trabalho investiga as condições de mobilidade ao Centro Acadêmico do Agreste - CAA, cujas atividades iniciaram em 2006. Foram realizadas seis pesquisas de campo: de contagem de veículos; de pessoas; de origem/destino; de opinião no transporte público; de opinião no transporte fretado; e de sobe-e-desce. Como principal resultado, aponta-se a atratividade do transporte fretado e sua importância para a consolidação do campus regional, com tempos de deslocamento semelhantes aos outros modos, para viagens até $40 \mathrm{~km}$, sendo também vantajoso para viagens maiores. O transporte fretado ainda possibilita a utilização do CAA por residentes em cidades até $100 \mathrm{~km}$, sem forçar a mudança de moradia para locais mais próximos.
\end{abstract}

Palavras-chave: acessibilidade estudantil, transporte fretado, transporte para campus regional.

\begin{abstract}
The Brazilian policy for federal Higher Education Institutions within the last 10 years set up the conditions to open two new campuses of the Universidade Federal de Pernambuco in two municipalities of the state. It is observed, however, that these municipalities offer precarious urban and regional transport services, impacting on users' access to these educational structures as well as affecting the students' academic performance. This paper investigates the mobility conditions of the Centro Acadêmico do Agreste - CAA, whose activities started in 2006. Six surveys were undertaken: vehicle count; people count; origin / destination; opinion on public transport; opinion on charter transportation; and boarding and alighting surveys. The highly attractiveness of chartered transport and its importance for the consolidation of a regional campus, with similar times to other modes of transport, for travel up to $40 \mathrm{~km}$, is the main result of this research. The charter transport also allows the access to CAA for those residents in cities up to $100 \mathrm{~km}$, without the need for housing to nearby locations.
\end{abstract}

Keywords: student accessibility, charter transportation, transport to regional campus.

\section{INTRODUÇÃO}

O ensino superior público brasileiro tem um passado caracterizado pela centralização de suas estruturas localizadas nas grandes cidades, com oferta limitada de vagas e de número de cursos disponíveis. Segundo Martins (2002), no início dos anos de 1960 o sistema educacional contava com aproximadamente cem instituições, a maioria delas de pequeno porte, localizadas, predominantemente, nos centros urbanos maiores, voltadas para atividades de transmissão do conhecimento e contando com um corpo docente com escassa profissionalização acadêmica. Esses estabelecimentos abrigavam pouco mais de 100 mil estudantes, a maioria do gênero masculino. $\mathrm{O}$ acesso às Instituições de Ensino

\footnotetext{
1 Leonardo Herszon Meira, Departamento de Engenharia Civil, Área de Transportes e Gestão das Infraestruturas Urbanas, Centro de Tecnologia e Geociências da Universidade Federal de Pernambuco, UFPE (leonardohmeira@gmail.com)

2 Maurício Oliveira de Andrade, Departamento de Engenharia Civil, Área de Transportes e Gestão das Infraestruturas Urbanas, Centro de

Tecnologia e Geociências da Universidade Federal de Pernambuco, UFPE (mauandrade@gmail.com)

${ }^{3}$ Maria Leonor Alves Maia, Departamento de Engenharia Civil, Área de

Transportes e Gestão das Infraestruturas Urbanas, Centro de Tecnologia e Geociências da Universidade Federal de Pernambuco, UFPE

(nonamaia@gmail.com)

${ }^{4}$ Anísio Brasileiro, Departamento de Engenharia Civil, Área de

Transportes e Gestão das Infraestruturas Urbanas, Centro de Tecnologia e

Geociências da Universidade Federal de Pernambuco, UFPE

(anisiobfd@hotmail.com)
}

Manuscrito recebido em 13/04/2014 e aprovado para publicação em 30/12/2014.

Este artigo é parte de TRANSPORTES v. 23 , n. 1, 2015. ISSN: 2237-1346

(online). DOI: 10.14295/transportes.v23i1.776
Superior - IES tornava-se uma barreira a ser vencida para os alunos residentes em áreas distantes desses centros, decorrente, dentre outros aspectos, dos custos de deslocamentos e de manutenção durante o período de realização do curso.

No entanto, nos últimos anos, a interiorização das IES - notadamente as públicas - e a ampliação de vagas alteraram, muito provavelmente, a dinâmica de acesso ao ensino superior. Desde o lançamento do programa do Governo Federal chamado REUNI foram criados 126 novos campi universitários, passando dos 148 existentes até 2002 para 274 em 2010 e com previsão de chegar aos 321 em 2014. Hoje, as universidades federais estão presentes em 237 municípios e o número de vagas passou de 109,2 mil em 2003 para 222,4 mil em 2010 (BRASIL, 2013). Muitas dessas estruturas universitárias criadas a partir do REUNI foram instaladas em municípios que ofertam, de forma precária, ou mesmo não ofertam, serviços de transporte público urbano e regional para a população, essencial para o acesso dos usuários a essas estruturas.

Com o REUNI, a Universidade Federal de Pernambuco - UFPE, que dispunha apenas de um campus no Recife, amplia sua atuação, com a instalação de mais dois campi: o Centro Acadêmico do Agreste - CAA, na cidade de Caruaru (que fica a $140 \mathrm{~km}$ do Recife) e o Centro Acadêmico de Vitória - CAV, em Vitória de Santo Antão (distando $60 \mathrm{~km}$ do Recife). O caráter regional desses novos campi revela, como uma questão fundamental, a importância de estudar as condições de mobilidade dos estudantes, 
entendendo suas necessidades, perspectivas e sua origem socioeconômica.

Este trabalho investiga as condições de mobilidade, em particular dos discentes ao CAA, cujas atividades iniciaram em 2006. Segundo os dados da matrícula escolar, no início de 2013 estudavam no CAA alunos provenientes de mais 70 municípios. Contudo, observa-se que, geralmente, as ligações entre a origem desses discentes e o CAA não são atendidas por transporte público regular nos horários desejados. Dada essa situação, as questões que se colocam nesse trabalho dizem respeito a como os usuários resolvem suas necessidades de deslocamento até o CAA e qual a importância do transporte público na consolidação de campi universitários regionais com essas características.

O objetivo principal deste trabalho é analisar o perfil das viagens diárias (casa-universidade) em termos de modos de transporte utilizados, das origens e dos tempos de deslocamento. Para uma análise qualitativa também é importante conhecer as condições das infraestruturas locais, como pontos de embarque, desembarque e estacionamento, a capacidade e os níveis de serviço de operação das vias de acesso e a oferta de transporte público. $\mathrm{O}$ aprofundamento destas questões possibilitará aos gestores da UFPE - e, eventualmente, de outros campi com características regionais semelhantes - analisar a atratividade da localização do CAA, propor medidas para aumentar a mobilidade e, assim, ampliar a capacidade de atendimento.

Este trabalho está estruturado em cinco seções. Após esta introdução, há uma descrição da região onde se insere o CAA - objeto deste estudo empírico - e uma caracterização do campus, enquanto polo gerador de viagens. A terceira seção descreve os métodos utilizados para coleta e processamento dos dados que consistiram especificamente de seis pesquisas de campo realizadas nos anos 2011, 2012 e 2013. Os resultados encontrados estão demonstrados em sequência, na quarta seção. Por fim, a quinta seção tece as considerações finais.

\section{O AGRESTE PERNAMBUCANO E O CENTRO ACADÊMICO DO AGRESTE}

O Agreste Pernambucano estende-se por uma área de $24.400 \mathrm{~km}^{2}$. Abrange 71 municípios, representa 24,7\% do território do Estado e tem cerca de 1.800 .000 habitantes, ou $25 \%$ da população pernambucana. As cidades mais populosas da região são (IBGE, 2010): Caruaru, Garanhuns e Santa Cruz do Capibaribe, com 314.912, 129.408 e 87.582 habitantes, respectivamente.

Quanto à educação, em 2008, a região possuía 15 IES, incluindo instituições federais, estaduais, municipais, particulares e filantrópicas, muito embora apresentasse um quadro de baixa escolaridade de sua população, da qual mais de 50\% (895.493 de 1.536 .565 habitantes com mais de 10 anos) possuía até 7 anos de estudos, não concluindo sequer o ensino médio (CONDEPE-FIDEM, 2011a).

Quanto ao emprego, apenas $10 \%$ da população da região trabalha formalmente. Em contraste, trata-se de uma região que vem experimentando altas taxas de crescimento econômico. Em termos de Produto Interno Bruto - PIB, Pernambuco e o Agreste vêm crescendo mais que o Brasil. A variação do PIB trimestral a preços de mercado $\left(1^{\circ}\right.$ trimestre de 2011) em comparação com o mesmo período de
2010 mostra que Pernambuco cresceu 7,6\%, enquanto o Brasil cresceu 4,2\% (CONDEPE-FIDEM, 2011b). No caso do Agreste, seu PIB per capita cresceu mais de $120 \%$ entre 2001 e 2008, passando de $\mathrm{R} \$ 6.159,00$ para $\mathrm{R} \$ 13.575,00$. Esse crescimento tende a potencializar o acesso ao ensino de nível superior, pela busca de melhor qualificação dos recursos humanos e do avanço da ciência e tecnologia.

O CAA está localizado ao norte da zona urbana do município de Caruaru. Fica a $8 \mathrm{~km}$ do centro da cidade, com acesso pela BR-104-PE e a $138 \mathrm{~km}$ do Recife, com acesso pela BR-232-PE. Ressalta-se que essas rodovias foram recentemente duplicadas (em 2012 e 2004, respectivamente). Portanto, essas vias trabalham com bons níveis de serviço, conferem boa acessibilidade e, consequentemente, não apresentam problemas de capacidade.

No primeiro semestre de 2014, funcionavam no CAA 10 cursos de graduação e 4 de pós-graduação, atendendo a 3.478 alunos de graduação e a 143 de pós-graduação, em turmas diurnas e noturnas. O CAA ainda possui cerca de 180 docentes e 60 servidores técnico-administrativos. Portanto, o campus apresenta características de um Polo Gerador de Viagens - PGV.

Os PGVs podem ser definidos como empreendimentos nos quais se desenvolvem atividades, em porte e escala, capazes de exercer grande atratividade na população e produzir um contingente significativo de viagens. Em geral, demandam espaços para estacionamento, para carga/descarga e para embarque/desembarque. Podem causar impactos positivos, como impulsionar o desenvolvimento de áreas urbanas, por trazer benefícios socioeconômicos e culturais e acessibilidade a produtos e bens diversos, ou negativos, dentre os quais se destacam a rápida saturação do sistema viário, principalmente nas vias de acesso ao empreendimento, e, consequentemente, congestionamentos, poluição, ruídos, vibrações e acidentes de trânsito (MAIA et al, 2010).

\section{PESQUISAS DE CAMPO REALIZADAS}

Para caracterizar a mobilidade deste PGV, em um dia típico, foram realizadas, em maio e junho de 2011, três pesquisas consideradas como integrantes da primeira etapa do trabalho: (1) contagem volumétrica de veículos; (2) contagem volumétrica de pessoas; e (3) pesquisa origem/destino - O/D com alunos, docentes, servidores e prestadores de serviço.

A partir da distribuição modal revelada pelas primeiras pesquisas, percebeu-se a enorme importância dos meios coletivos (77\% dos usuários os utilizam), especialmente o transporte por fretamento para os residentes nos municípios do entorno e do transporte público regular para os residentes de Caruaru. Por essa razão, foram realizadas duas pesquisas complementares, consideradas como segunda etapa do trabalho, para: (1) aferir a opinião dos usuários do transporte fretado e do transporte público regular em Caruaru, realizadas em outubro de 2012 e março de 2013, respectivamente; e (2) uma pesquisa sobe-e-desce, realizada em abril de 2013, na única linha de ônibus que atende ao campus, para avaliar os problemas operacionais de superlotação descritos pelos usuários do transporte público regular. A seguir, são descritas as pesquisas realizadas.

$1^{\mathrm{a}}$ etapa do trabalho: 
1. A contagem volumétrica veicular foi realizada no único acesso do CAA, com classificação dos veículos em automóvel, táxi, motocicleta, mototáxi, ônibus urbano, ônibus fretado, van fretada e bicicleta. Foi realizada no dia 15/05/2011, no período das 07 às $22 \mathrm{~h} 30 \mathrm{~min}$, representativo do funcionamento da instituição.

2. A contagem dos acessos de pessoas ao CAA foi realizada na única entrada do centro. A pesquisa foi realizada no dia 22/06/2011, também no horário das 07 às $22 \mathrm{~h} 30 \mathrm{~min}$.

3. A pesquisa $\mathrm{O} / \mathrm{D}$, realizada entre os meses de maio e junho de 2011, foi feita com a aplicação de um questionário que buscou levantar informações sobre os modos de transporte utilizados, origens das viagens, horários de chegada e saída, número de pessoas por veículo e utilização de estacionamento. Como é conhecida a população usuária do campus e a média $(35 \mathrm{~km})$ e desvio padrão $(39 \mathrm{~km})$ da distância de viagem da população, obtidos nos registros da matrícula de alunos, aplicou-se na definição do tamanho da amostra a equação 1 para populações finitas, considerando-se um grau de confiança de $94 \%$ e erro amostral de $6 \%$.

$$
n=\frac{N \sigma^{2}\left(\frac{Z \alpha}{2}\right)^{2}}{(N-1) E^{2}+\sigma^{2}\left(\frac{Z \alpha}{2}\right)^{2}}
$$

Onde:

$n$ : tamanho da amostra;

$N$ : população (3.000 pessoas);

$\sigma:$ desvio-padrão da população;

$\frac{Z \alpha}{2}$ : valor crítico que corresponde ao grau de confiança desejado de 1,88; e

$E$ : margem de erro sobre a distância média de viagem da população, $2,18 \mathrm{~km}$.

O tamanho da amostra então obtida, com base nas condições estabelecidas, foi de 818 entrevistas. A amostra foi dividida proporcionalmente entre as partes e os turnos de trabalho (diurno e noturno), com 725 alunos, 60 professores, 20 técnico-administrativos e 13 prestadores de serviço. Os questionários foram aplicados na semana de 31/05 a 03/06/2011. $2^{a}$ etapa do trabalho:

1. A pesquisa de opinião com os alunos usuários do transporte fretado consistiu na realização de entrevista procurando conhecer seu perfil, tipo de veículo e perfil da viagem em relação a custos (tarifa ou subsídio público) e a tempo de deslocamento. Adicionalmente, procurou-se identificar a percepção destes usuários com relação à qualidade e conveniência deste tipo de transporte e os impactos sobre o desempenho nas atividades universitárias. A pesquisa foi realizada entre os dias 01 e 05/10/2012.

Os questionários foram aplicados na chegada dos alunos ao CAA. Para melhor distribuir a amostra eram escolhidos aleatoriamente dois indivíduos chegando em vans, três em micro-ônibus e cinco em ônibus. $\mathrm{O}$ número de entrevistas foi dividido proporcionalmente, baseando-se no número de alunos por turno ( $60 \%$ no noturno e $40 \%$ no diurno). A estrutura do questionário foi desenvolvida em tópicos, conforme a seguir:

○ Identificação: sexo, idade, curso e horário das aulas;

o Renda familiar: classificada em grupos relacionados com o salário mínimo brasileiro;

o Características de viagem: origem, horário de partida e chegada ao CAA e tipos de veículos utilizados;

o Custos mensais de transporte, forma e responsabilidade do pagamento (diretamente pelo usuário, assistência estudantil da universidade ou do município);

- Razões para a escolha modal, considerando despesas de viagem, conforto, regularidade, trajetos diretos, conveniência de horário, distância, viajar com os colegas e a falta de opções melhores;

○ A possível consequência da utilização deste tipo de transporte, em termos de tempo e conveniência em relação à frequência de atrasos, baixa frequência, estresse físico/emocional ou redução da motivação para prosseguir os estudos; e

o Declaração dos usuários do transporte fretado em relação ao nível de impacto estimado em seu desempenho escolar.

2. A pesquisa de opinião no transporte público regular urbano foi realizada com um questionário estruturado em perguntas sobre os principais problemas e suas consequências na rotina universitária. Foi também solicitada uma hierarquização entre algumas alternativas que foram fornecidas para a solução e/ou mitigação de eventuais problemas no transporte.

A definição do tamanho da amostra a ser entrevistada baseou-se em pesquisa realizada por Andrade et al (2013) que verificou por contagem de dois dias representativos, que cerca de $34 \%$ dos estudantes acessavam o campus por transporte coletivo regular. Então, buscando-se assegurar um intervalo de confiança mínimo de $90 \%$, a amostra calculada sobre uma população usuária de cerca de 1.200 estudantes foi de 398 entrevistas, calculada pela Equação 1. A pesquisa foi realizada no dia 05/03/2013, das 07 às $22 \mathrm{~h} 30 \mathrm{~min}$.

3. A pesquisa sobe-e-desce foi realizada na única linha de transporte público regular que atende ao CAA, com o objetivo de testar as condições de operação da linha. O método utilizado foi constituído de duas etapas: (1) identificação dos pontos de parada do itinerário; e (2) entrega, por parte dos pesquisadores, de um cartão a cada um dos usuários que entravam nos ônibus. Esses cartões continham a identificação do ponto de embarque utilizado por cada usuário. Quando o usuário desembarcava esses cartões eram recolhidos e separados de acordo com o ponto de desembarque. Desta maneira, se tornou possível conhecer o número de passageiros que subiram em cada parada e onde esses usuários desembarcaram, permitindo a construção de uma matriz O/D para cada faixa de horário. A pesquisa foi realizada entre os dias 09 e 11/04/2013, das 07 às 22h30min. 


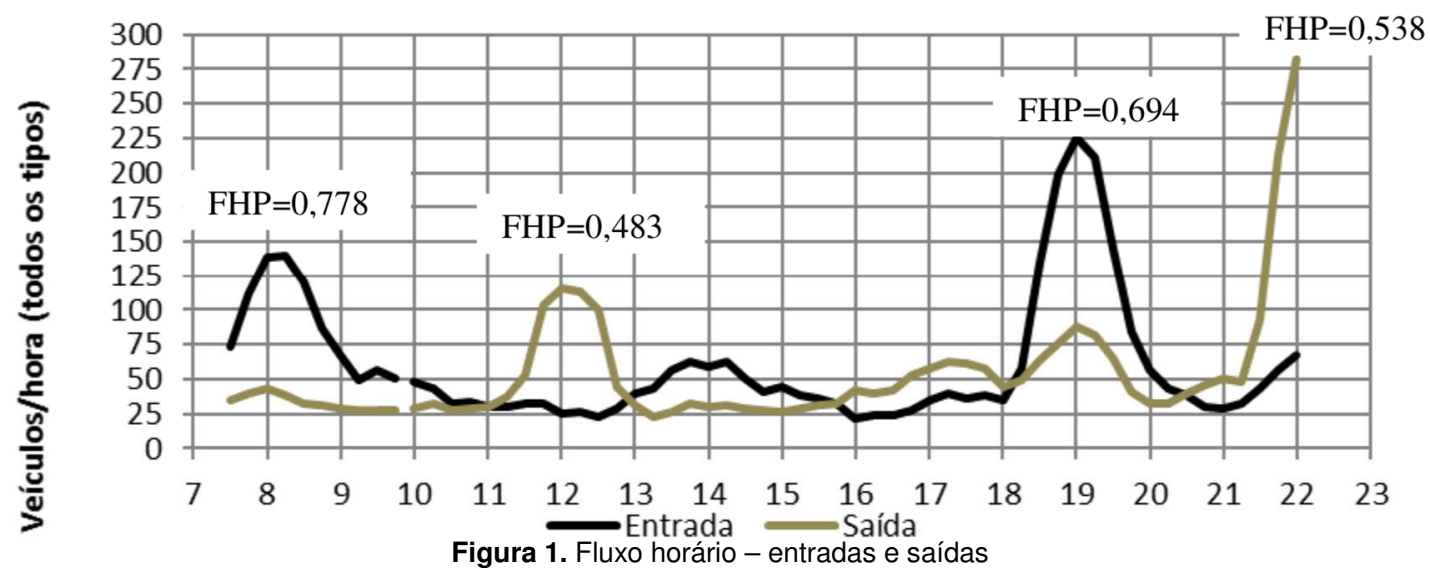

\section{RESULTADOS}

De forma a facilitar o entendimento, os dados levantados nas três primeiras pesquisas de caracterização do PGV foram compilados e serão mostrados, de forma agregada, a seguir.

\subsection{Contagem volumétrica de veículos e pedestres e pesquisa O/D}

Inicialmente, pode-se colocar que o perfil levantado na pesquisa $\mathrm{O} / \mathrm{D}$ das origens dos usuários reflete o caráter regional do CAA. Pela amostra da pesquisa, acessam diariamente, além dos residentes em Caruaru (distância inferior a $20 \mathrm{~km}), 45 \%$ de estudantes de 41 municípios, com distâncias de transporte que variam de 20 a $40 \mathrm{~km}$ (10\% do total), de 41 a $60 \mathrm{~km} \mathrm{(15 \% )} \mathrm{e} \mathrm{de} 61$ a $80 \mathrm{~km}(6,5 \%)$. No outro limite, observou-se que quase $10 \%$ dos usuários percorrem acima de $100 \mathrm{~km}$ todos os dias. A distância média de viagem calculada, a partir da amostra, foi de $35,5 \mathrm{~km}$.

Com base nas contagens, 2.630 pessoas entraram no CAA nos dias pesquisados, em 938 veículos. A Figura 1 mostra as variações nos fluxos de entrada e saída de veículos no CAA. A partir dos valores máximos desses intervalos e dos Fatores de Hora de Pico - FHP observa-se grande concentração do fluxo em poucos minutos, sobretudo nos picos de saída.

Pela pesquisa, a relação entre o número diário de pessoas atraídas e a população usuária do campus é de 0,859 viagens/usuário/dia, enquanto que esta mesma relação com o número de alunos é de 0,939. Comparando-se essas taxas de viagens produzidas e atraídas pelo CAA com os resultados sugeridos por estudos anteriores do TECTRAN (2003a, 2003b e 2004) para IES situadas em áreas com boa infraestrutura viária e servidas por transporte público, obtêm-se resultados de geração muito próximos, como mostrados a seguir:
- Para um conjunto de 1.000 usuários são atraídas e produzidas 1.710 viagens diárias (TECTRAN, 2004), que coincidem praticamente, com o número de 1.720 viagens para o CAA;

- 1.000 alunos (IES), na hora de pico, atraem 910 acessos de pessoas $(\mathrm{V}=1.710 \times \mathrm{NU} \times \mathrm{FHP})$ segundo o TECTRAN (2003a), em comparação a 847 acessos de pessoas por hora na contagem do CAA.

- 1.000 alunos (IES), na hora de pico, produzem 993 saídas de pessoas $(\mathrm{V}=1.710 \times \mathrm{NU} \times \mathrm{FHP})$, segundo o TECTRAN (2003b), em comparação a 1.060 saídas de pessoas por hora na contagem do CAA.

Comparando-se os dados relativos à atração de viagens de 432 pessoas no pico da noite do CAA com a aplicação do modelo da CET (1983) para instituições de ensino em geral com menos de 13.000 alunos $\left(\mathrm{V}=0,432 \mathrm{x} \mathrm{n}^{\circ}\right.$. de alunos - 106,303), que relaciona o volume no pico na entrada com o número de alunos no turno, obtém-se praticamente o mesmo resultado, ou seja, 444 pessoas/hora. Então, tanto com relação ao número de viagens geradas e atraídas por dia quanto por hora de pico conclui-se serem válidos para o CAA os modelos de geração do TECTRAN e da CET.

Observando a distribuição modal, pode-se colocar que a contagem no estacionamento definiu o padrão de distribuição entre os diversos tipos de veículos utilizados em um dia típico, conforme a Tabela 1.

Observa-se que apesar do grande predomínio de veículos de transporte individual (73,2\% - automóveis e motos) em comparação a veículos de transporte coletivo (23\% - ônibus urbano, ônibus e vans fretadas), os mesmos transportam $76,7 \%$ dos usuários e o transporte individual apenas $22,8 \%$.

Destaca-se ainda, que o número de vans ou ônibus fretados representa $82 \%$ dos acessos de veículos de transporte coletivo até o CAA. Analisando o percentual de passageiros transportados apenas pelo transporte coletivo, verifica-se que $44,3 \%$ utilizam o transporte público regular e

Tabela 1. Distribuição modal dos acessos e das viagens atraídas ao CAA

\begin{tabular}{|c|c|c|c|c|c|c|c|c|c|}
\hline & Auto & Táxi & Moto & $\begin{array}{l}\text { Moto- } \\
\text { táxi }\end{array}$ & $\begin{array}{l}\text { Onibus } \\
\text { Urbano }\end{array}$ & $\begin{array}{l}\text { Ônibus } \\
\text { Fretado }\end{array}$ & $\begin{array}{l}\text { Vans } \\
\text { Fretadas }\end{array}$ & $\begin{array}{l}\text { Cargal } \\
\text { outros }\end{array}$ & Total \\
\hline Veículos & 543 & 5 & 142 & 27 & 39 & 49 & 127 & 6 & 938 \\
\hline Percentual & $57,89 \%$ & $0,53 \%$ & $15,14 \%$ & $2,88 \%$ & $4,16 \%$ & $5,22 \%$ & $13,54 \%$ & $0,64 \%$ & $100 \%$ \\
\hline Usuários & 487 & 3 & 119 & 3 & 893 & 350 & 772 & 3 & 2.630 \\
\hline Percentual & $18,52 \%$ & $0,12 \%$ & $4,51 \%$ & $0,12 \%$ & $33,95 \%$ & $13,31 \%$ & $29,35 \%$ & $0,12 \%$ & $100 \%$ \\
\hline
\end{tabular}




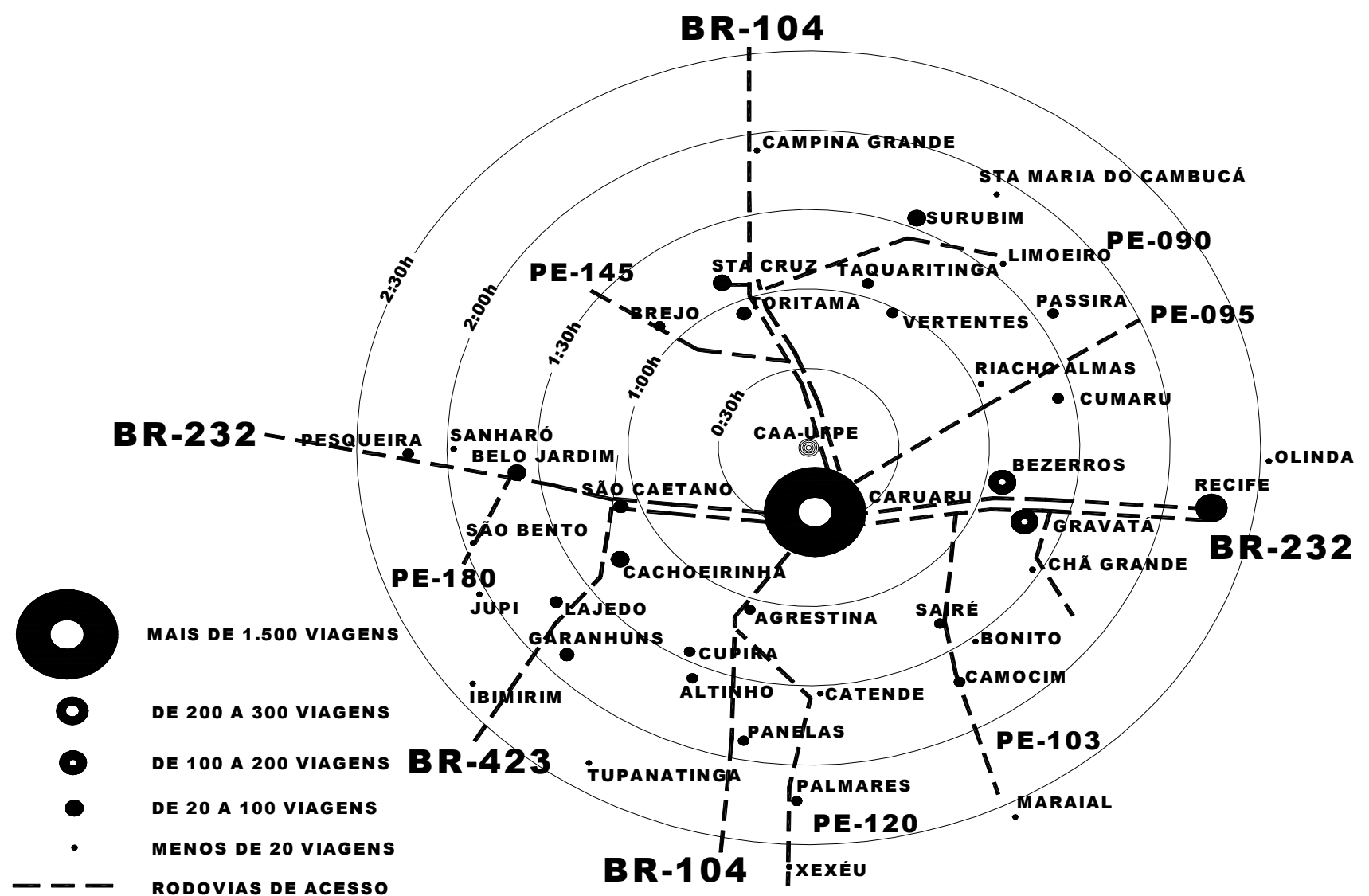

Figura 2. Isócronas em relação ao CAA

$55,7 \%$ o transporte fretado. Esses números mostram a importância do transporte fretado para o caso analisado, em face da dispersão nas diversas origens dos usuários, com consequente pulverização da demanda em itinerários e horários de utilização adequados a pequenos grupos de alunos. Esta particularidade parece ser o grande diferencial do CAA em relação a outros estudos relatados na literatura pesquisada.

Sob este enfoque, vários estudos realizados em IES pela Rede Ibero-Americana de Estudos em PGV (BERTAZZO et al, 2010) demonstram resultados que diferem sensivelmente dos obtidos no CAA. Por exemplo, o transporte por automóvel no CAA representa $18,5 \%$ das viagens, que se aproxima dos $19,8 \%$ dos estudos de Herz et al (2007, 2009) em Córdoba (Argentina), mas difere fortemente de outros estudos realizados pela TECTRAN (2003) em Belo Horizonte, e por Nunes (2005) e Souza (2007) no Distrito Federal, com resultados de $35 \%$ a $45 \%$ e $50 \%$ a $60 \%$, respectivamente. Outro fator interessante, que deve estar relacionado à localização dos campi, é o percentual de viagens a pé, que no caso do CAA, por estar localizado longe da zona urbana é praticamente inexistente, enquanto que o mesmo, varia entre $11 \%$ a $17 \%$ nos estudos do TECTRAN (2003), 5,5 a 7,2\% nos estudos de Nunes (2005) e Souza (2007) e 29\% nos estudos de Herz et al (2007, 2009). O transporte urbano regular utilizado por $33,95 \%$ no CAA é menos significativo do que os cerca de $40 \%$ nos estudos do TECTRAN (ibid) e $45 \%$ nos estudos de Herz et al (ibid) e se aproxima dos valores dos estudos de Souza (ibid), de $31 \%$. Então, pode-se inferir que a característica diferenciada da mobilidade do CAA, em relação aos estudos relatados, é a expressiva participação $(42,7 \%)$ do transporte fretado.
Outro aspecto relevante a considerar na acessibilidade ao CAA são as características das viagens em termos de tempo de deslocamento e velocidade média, a partir das diversas origens e modos de transporte. Essa análise foi realizada pela definição de isócronas - linhas que ligam pontos com igual distância de viagem (em minutos) ao PGV (Figura 2) - com representação espacial da posição dos municípios em relação ao CAA, com base nos tempos médios de viagem, subdivididos em intervalos de 30 minutos. $\mathrm{Na}$ mesma figura está representado o peso relativo das viagens diárias com origem em cada município. Observa-se que, com exceção das viagens com origem na Região Metropolitana do Recife, a maioria dos deslocamentos parte de municípios localizados até $01 \mathrm{~h} 30 \mathrm{~min}$ de tempo médio de viagem. Observa-se também que as viagens se concentram mais fortemente nos municípios atravessados por rodovias de melhor nível de serviço (classes 1 e 1A do DNIT).

Uma das razões que podem justificar a viabilidade da atração de viagens ao CAA a distâncias maiores é a maior velocidade média do deslocamento. $\mathrm{O}$ estudo demonstra que, apesar das variações em uma análise que considera todos os modos de transporte, a velocidade média cresce a uma taxa de $4 \mathrm{~km} / \mathrm{h}$ a cada $10 \mathrm{~km}$ de aumento da distância de viagem. Por exemplo, a velocidade média das viagens com distância de $20 \mathrm{~km}$ é de $22 \mathrm{~km} / \mathrm{h}$, enquanto que, para a distância de $140 \mathrm{~km}$, a velocidade média passa para cerca de $70 \mathrm{~km} / \mathrm{h}$. Distâncias maiores em rodovias duplicadas e sem paradas produzem viagens com tempos de deslocamento aceitáveis, viabilizando a manutenção da residência do usuário em sua cidade de origem.

O estudo também mostra que os transportes fretados apresentam velocidade média de quase $40 \mathrm{~km} / \mathrm{h}$ (Tabela 2), 
MEIRA, L.H.; ANDRADE, M.O.; MAIA, M.L.A.; BRASILEIRO, A.

Tabela 2. Distâncias, velocidades e distribuição modal em função da distância

\begin{tabular}{llllll}
\hline Distância $(\mathbf{k m})$ & Auto & Moto & Onibus regular & Onibus fretado & Vans \\
\hline Até 20 & $75,0 \%$ & $91,6 \%$ & $85,8 \%$ & $13,8 \%$ & $24,5 \%$ \\
De 21 a 40 & $3,4 \%$ & $2,8 \%$ & $7,6 \%$ & $9,8 \%$ & $18,6 \%$ \\
De 41 a 60 & $5,4 \%$ & $5,6 \%$ & $4,7 \%$ & $41,2 \%$ & $22,8 \%$ \\
De 61 a 80 & $1,3 \%$ & - & $0,4 \%$ & $28,4 \%$ & $9,7 \%$ \\
De 81 a 100 & $2,7 \%$ & - & $0,3 \%$ & $5,8 \%$ & $2,5 \%$ \\
Mais de 100 & $12,2 \%$ & - & $1,1 \%$ & $1,0 \%$ & $21,9 \%$ \\
\hline Média & $12,2 \mathrm{~km}$ & $12,4 \mathrm{~km}$ & $14,4 \mathrm{~km}$ & $52,40 \mathrm{~km}$ & $59,4 \mathrm{~km}$ \\
\hline \% Médio & $18,52 \%$ & $4,51 \%$ & $29,54 \%$ & $13,26 \%$ & $34,17 \%$ \\
\hline Velocidade Mé- & $35 \mathrm{~km} / \mathrm{h}$ & $26,50 \mathrm{~km} / \mathrm{h}$ & $12,60 \mathrm{~km} / \mathrm{h}$ & $39,80 \mathrm{~km} / \mathrm{h}$ & $39,80 \mathrm{~km} / \mathrm{h}$ \\
dia & & & &
\end{tabular}

cerca de três vezes maior que o transporte por ônibus regular. Analisando-se esses dados pode-se concluir que residentes em cidades situadas a até $40 \mathrm{~km}$ do CAA apresentam tempos de viagem equivalentes aos obtidos pelos deslocamentos dos residentes em Caruaru, usuários do transporte público regular.

O perfil da demanda de viagens ao CAA revela a importância do transporte fretado para distâncias acima de 40 $\mathrm{km}$, ao transportar cerca de $30 \%$ dos usuários do campus (ver Tabela 2). O transporte por vans fretadas, por ser adequado a pequenas demandas, também se mostra expressivo nas distâncias curtas. Atende a quase $9 \%$ dos residentes em Caruaru e a cerca de $15 \%$, quando considerados os residentes a até $40 \mathrm{~km}$ do campus.

Então, pelas particularidades apresentadas pelo CAA no tocante ao uso do transporte fretado foi elaborada outra pesquisa, com o intuito de conhecer as características e a percepção dos usuários sobre este serviço.

\subsection{Pesquisa de opinião com os usuários do transporte fretado}

Analisando os dados coletados nesta pesquisa percebe-se que a renda familiar dos usuários do transporte fretado para o CAA difere fortemente da distribuição de renda familiar na Região Agreste Pernambucana. Enquanto $74,4 \%$ da população da região tem renda familiar de até 2 Salários Mínimos - SM, apenas 12,7 \% dos estudantes se encontram nessa faixa de renda. Além disso, a renda familiar média deste grupo é mais do que o dobro da renda média da população em geral. Isso pode ser explicado pelo fato de que há forte correlação entre o nível de educação formal e a renda familiar. Outra constatação é que entre os usuários de transporte fretado quase $70 \%$ pagam o operador com recursos próprios. Os demais $30 \%$ são pagos pelos municípios (14\%) e pela Universidade (16\%) por meio do Programa de Assistência Estudantil Auxílio Transporte.

Pode-se observar ainda que $33 \%$ dos alunos de famílias com renda de até $3 \mathrm{SM}$, usuários de transporte fretado, recebem assistência de transporte. Para atender a demanda de transporte de longa distância para essa faixa de renda, estima-se a necessidade de apoio financeiro para 660 alunos, o que equivale a um quarto dos alunos do CAA. Em 2012, a UFPE concedeu auxílio-transporte para 642 estudantes do CAA e cerca de 200 alunos (ou 14\% do total do transporte fretado) foram beneficiados pelo transporte fornecido pelos municípios. Portanto, esse número oferecido pelo programa de auxílio parece ser suficiente para a demanda atual.

Outra questão é que as diferenças de velocidades médias para a faixa de distância de 41 a $60 \mathrm{~km}$ entre o automó$\operatorname{vel}(56 \mathrm{~km} / \mathrm{h})$ e o transporte fretado $(42 \mathrm{~km} / \mathrm{h})$ mostram que a economia de tempo em uma viagem de $50 \mathrm{~km}$ fica em torno de 17 minutos, e mesmo sem considerar a renda média baixa dos usuários, não compensam as diferenças nos custos de viagem entre os dois modos. Extraindo-se dados das tabelas 1 e 2, vê-se que a opção pelo transporte fretado foi considerada mais vantajosa para cerca de $80 \%$ dos viajantes nesta faixa de distância. Apesar dessas escolhas, é importante frisar que os veículos que operam o serviço de transporte fretado na região do CAA - e no interior do Nordeste de uma maneira geral - possuem elevada média de idade e, por esta razão, podem não oferecer a qualidade necessária ao serviço.

Ao serem questionados sobre os principais atributos considerados na escolha modal, os usuários pagantes do transporte fretado destacaram: custo, regularidade, viagem

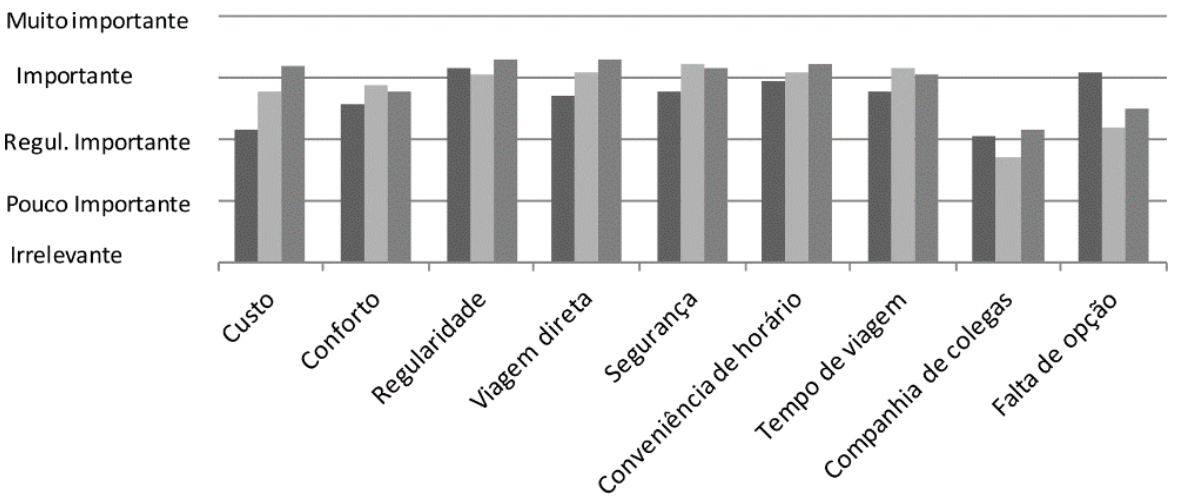

Provido pela prefeitura Subsidiado pela Universidade Pago pelo usuário Figura 3. Comparação de atributos de escolha de viagem por grupo de usuários 


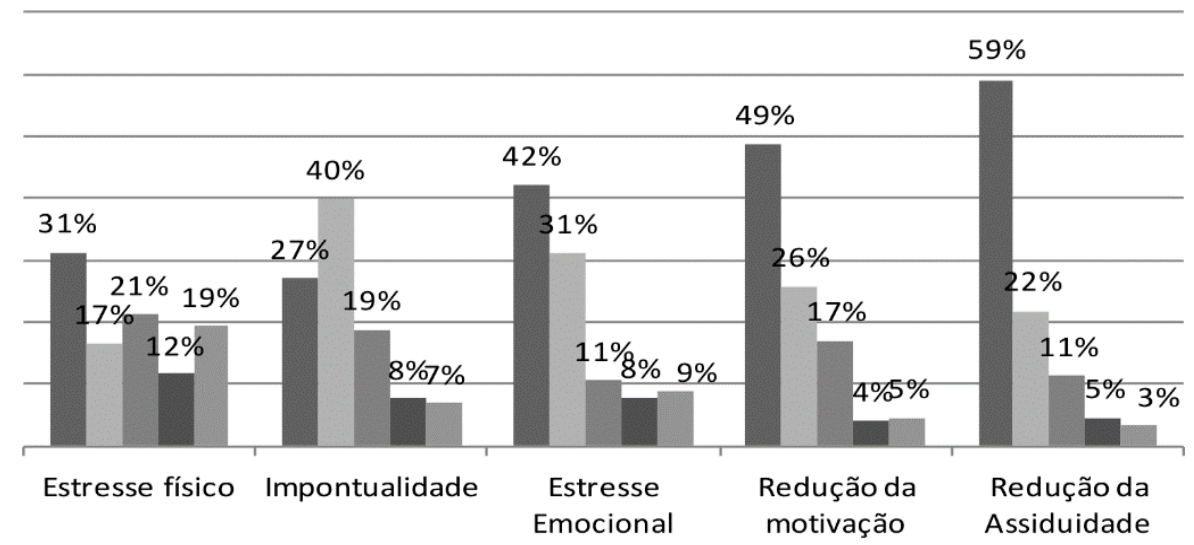

Nunca Raramente > de $1 \mathrm{vez} / \mathrm{mês}$ 口 > de uma vez / semana Sempre Figura 4. Comparação de atributos de escolha de viagem por grupo de usuários

direta e conveniência de horário. Os alunos cujo transporte foi subsidiado pela Universidade ou prefeituras deram importância regular aos custos, além de valorizarem menos do que os pagantes as viagens diretas e a conveniência dos horários (Figura 3).

O uso do transporte fretado produz atrasos sempre ou mais de uma vez por semana para15\% dos estudantes pesquisados, sendo que $8 \%$ do total chegaram a reduzir a assiduidade às aulas muito frequentemente, gerando um percentual equivalente de alunos que declararam redução de motivação para prosseguir nos estudos. Estresses físicos e emocionais devidos às condições de transporte são relatados por $31 \%$ e $17 \%$ dos alunos entrevistados, respectivamente. Apesar desses problemas, a grande maioria dos alunos apresenta elevada resiliência, principalmente quando $75 \%$ e $81 \%$ deles relata que nunca ou raramente se sentem desmotivados pelos estudos ou reduzem a assiduidade às aulas, respectivamente (Figura 4 ).

Diante das inúmeras dificuldades percebidas com relação ao transporte público regular urbano que atende ao CAA, também foi realizada uma pesquisa para aferir a opinião dos alunos sobre este serviço e que será mostrada na seção a seguir.

\subsection{Pesquisa de opinião na linha de transporte público regular}

Segundo esta pesquisa, seus usuários pertencem a famílias que apresentam um perfil de renda mensal representado por: $58,3 \%$ até $3 \mathrm{SM}, 28 \%$ entre 3 e 5SM, $11,3 \%$ entre 5 e $10 \mathrm{SM}$ e apenas $2,5 \%$ acima de $10 \mathrm{SM}$.

Como principais problemas apontados estão: longos tempos de espera, impontualidade e irregularidade na operação e mau estado de conservação dos ônibus (ver Tabela 3). Observa-se que o aumento desses incômodos está positivamente relacionado ao aumento da renda familiar, sugerindo, desta forma, que pode haver maior tolerância dos mais pobres em relação à baixa qualidade do transporte. A Tabela 3 mostra ainda que os problemas decorrentes do valor da tarifa e da falta de linhas alternativas afetam apenas aqueles provenientes de famílias com renda até $5 \mathrm{SM}$, que decorrem da maior vulnerabilidade econômica e da concentração dos mais pobres nas periferias, com baixa acessibilidade à única linha de acesso ao CAA, que atravessa áreas centrais e/ou de maior renda de Caruaru.
Analisando-se os problemas listados, de forma agregada por conjunto de problemas afins, observa-se: (1) inadequação do planejamento da linha de transporte urbano para o CAA (faltam linhas alternativas; frota incompatível com a demanda; intervalo ou tempo de espera; má conservação dos ônibus; má distribuição de horários; e superlotação), com 77,7\%; (2) deficiências na fiscalização da operação (impontualidade e irregularidade), com 18,7\%; (3) baixa qualidade nas infraestruturas viárias e de apoio, como pontos de parada e terminais (infraestrutura - vias, paradas), com 2,3\%; e (4) elevado valor da tarifa (tarifa alta), com $1,3 \%$. Ou seja, planejamento e fiscalização são os focos dos problemas mencionados, sendo ambos de competência da administração municipal.

Ao analisar a qualidade dos serviços ofertados pela linha de transporte público disponível vê-se que o tempo de espera é classificado como ruim/péssimo para cerca de $81 \%$ dos usuários. Este fato vem reforçar os principais problemas como de natureza de planejamento e fiscalização, como declaram mais de $95 \%$ dos entrevistados. Revela-se ainda que quase $50 \%$ dos usuários reclamam das condições de conforto dos veículos. Com relação à utilidade da linha, observa-se que $37 \%$ declararam ruim/péssimo o itinerário disponibilizado para os seus interesses, sugerindo daí, a necessidade de outra(s) alternativa(s). Esta situação coincide com o fato de que um número equivalente de alunos utiliza linhas auxiliares ao centro a partir de origens mais distantes do itinerário da linha. Apesar de não aparecer entre os principais problemas, na avaliação da qualidade do serviço, quando solicitados a responder sobre os custos de transportes, a avaliação demonstra que $60 \%$ dos usuários consideram a tarifa de transporte um fator fortemente negativo (ruim e péssimo) e neste número, certamente estão incluídos os usuários que precisam utilizar duas linhas de ônibus para chegar ao CAA.

\subsection{Pesquisa sobe-e-desce}

A pesquisa sobe-e-desce busca entender melhor as respostas dos usuários quanto à linha de transporte público que atende ao CAA. Ao analisar os dados, a primeira observação que se pode extrair é o forte movimento pendular entre os pontos extremos do itinerário da linha, ou seja, nas paradas da região central de Caruaru e na chegada ao CAA. Percebe-se que esses extremos concentram entre 85 e $100 \%$ dos acessos e descidas. Essa característica pendular se 
MEIRA, L.H.; ANDRADE, M.O.; MAIA, M.L.A.; BRASILEIRO, A.

Tabela 3. Problemas e consequências revelados com base na distribuição de renda familiar

\begin{tabular}{|c|c|c|c|c|c|c|c|c|c|}
\hline Problemas & $\begin{array}{l}\text { Faltam } \\
\text { linhas al- } \\
\text { ternat. }\end{array}$ & $\begin{array}{l}\text { Frota } \\
\text { incomp. } \\
\text { com a } \\
\text { demanda }\end{array}$ & $\begin{array}{l}\text { Infra- } \\
\text { estrutura } \\
\text { (vias, pa- } \\
\text { radas) } \\
\end{array}$ & $\begin{array}{l}\text { Intervalo } \\
\text { ou tempo } \\
\text { de espera }\end{array}$ & $\begin{array}{l}\text { Impont.e } \\
\text { irregul. }\end{array}$ & $\begin{array}{l}\text { Má con- } \\
\text { serv. dos } \\
\text { ônibus } \\
\end{array}$ & $\begin{array}{l}\text { Má dis- } \\
\text { trib. de } \\
\text { horários }\end{array}$ & $\begin{array}{l}\text { Super- } \\
\text { lotação }\end{array}$ & $\begin{array}{l}\text { Tarifa } \\
\text { alta }\end{array}$ \\
\hline Até $3 \mathrm{SM}$ & $7,0 \%$ & $12,7 \%$ & $2,2 \%$ & $27,1 \%$ & $14,8 \%$ & $1,7 \%$ & $11,4 \%$ & $22,3 \%$ & $0,9 \%$ \\
\hline De 3 a 5 SM & $6,1 \%$ & $13,9 \%$ & $2,6 \%$ & $34,8 \%$ & $15,7 \%$ & $3,5 \%$ & $5,2 \%$ & $16,5 \%$ & $1,7 \%$ \\
\hline De 5 a 10 SM & $0,0 \%$ & $6,7 \%$ & $2,2 \%$ & $37,8 \%$ & $20,0 \%$ & $6,7 \%$ & $2,2 \%$ & $24,4 \%$ & $0,0 \%$ \\
\hline +de 10 SM & $0,0 \%$ & $8,3 \%$ & $0,0 \%$ & $41,7 \%$ & $25,0 \%$ & $0,0 \%$ & $8,3 \%$ & $16,7 \%$ & $0,0 \%$ \\
\hline
\end{tabular}

\begin{tabular}{lllll} 
Consequências & $\begin{array}{l}\text { Atraso e perda de ativi- } \\
\text { dades }\end{array}$ & Desgaste físico e estresse & $\begin{array}{l}\text { Impacto da tarifa sobre a } \\
\text { renda }\end{array}$ & Tempo Ocioso \\
\hline Até 3 SM & $70,3 \%$ & $10,8 \%$ & $5,4 \%$ & $13,5 \%$ \\
De 3 a 5 SM & $60,4 \%$ & $19,8 \%$ & $0,9 \%$ & $18,9 \%$ \\
De 5 a 10 SM & $62,2 \%$ & $15,6 \%$ & $0,0 \%$ & $22,2 \%$ \\
+ de 10 SM & $72,7 \%$ & - & - & $27,3 \%$ \\
\hline
\end{tabular}

reforça quando se verifica que os picos são fortemente influenciados pelo início e final dos turnos diurno e noturno, deixando claro que a linha deve (ou deveria) ser planejada com foco exclusivo no atendimento às demandas do campus. A Tabela 4 evidencia essa observação em termos de passageiros desembarcados na viagem pesquisada e expandidos para passageiros por hora, a partir da frequência da linha, com forte demanda de concentração de acessos e descidas nos extremos da linha.

Pode-se constatar que as paradas situadas às margens da BR-104-PE não apresentam embarques e desembarques significativos. Desta forma, pode-se propor que, pelo menos nos horários de pico dos movimentos ao campus, a linha se torne expressa, suprimindo os pontos de parada ao longo de toda a BR-104-PE. Este trecho está em excelentes condições de tráfego, é atendido por outras linhas de transporte público regular e se pode desenvolver velocidades operacionais maiores, reduzindo desta forma, os tempos totais de viagens e os inconvenientes de eventuais viagens em pé mais demoradas. Com a mesma abordagem de carregamento dos ônibus nos diversos trechos e nas demandas horárias do CAA pode-se concluir que, durante os períodos fora de pico (09 às 11 h e 14 às 17 h), não há necessidade atual de modificar os intervalos ou restringir a operação das paradas ao longo da BR-104-PE.

\section{CONSIDERAÇÕES FINAIS}

Os resultados da pesquisa demonstram que o CAA é um campus universitário de caráter regional que atende a várias cidades, com aproximadamente $45 \%$ das vagas ocupadas por alunos residentes em outros municípios.

Observa-se, contudo, que há uma ineficiência no transporte público que atende aos estudantes, com intervalos longos, serviço precário e irregular. São comuns usuários que moram e se deslocam de outros municípios para o CAA e gastam o mesmo ou até menos tempo para acessar o campus em relação aos usuários moradores de Caruaru. Como exemplo, pode-se citar o bairro Inocoop, onde os passageiros de transporte coletivo gastam em média $75 \mathrm{minu}-$ tos para um percurso de $11,8 \mathrm{~km}$ até o campus, o mesmo tempo gasto pelos usuários que habitam na cidade de $\mathrm{Cu}$ pira, que dista $46 \mathrm{~km}$ do CAA. Isto provavelmente ocorre pelo fato do CAA estar localizado na área periférica da zona urbana de Caruaru, longe do centro e margeado por uma rodovia com bom nível de serviço que interliga outros municípios e cuja velocidade é maior do que aquela dos veículos que circulam na área urbana de Caruaru.

Os resultados mostram que para acessar o campus, um grande número de alunos busca o transporte fretado, que acaba sendo o modo mais frequente de transporte. Essa é uma característica de mobilidade até então não observada nos estudos de mobilidade para IES no Brasil, mas nada leva a crer que essa situação não possa se repetir em outros campi interioranos de caráter regional.

O transporte fretado é usado não somente como única alternativa de transporte hoje disponível para 42,66\% dos estudantes do CAA, mas também é a opção mais barata face a renda per capita da região e ao perfil disperso da demanda. Não se pode ignorar, contudo, que esta é uma opção de mobilidade sustentável para esse PGV e que, portanto, torna-

Tabela 4. Caracterização do movimento casa-Universidade no CAA

\begin{tabular}{|c|c|c|c|c|c|c|c|}
\hline \multicolumn{2}{|l|}{ Horários } & \multicolumn{2}{|c|}{$\begin{array}{l}\text { Acesso no Centro e des- } \\
\text { cida no } C A A\end{array}$} & \multicolumn{2}{|c|}{$\begin{array}{l}\text { Acesso no CAA e des- } \\
\text { cida no Centro }\end{array}$} & \multirow{2}{*}{$\begin{array}{l}\text { Intervalo médio } \\
\text { dos ônibus (min) }\end{array}$} & \multirow{2}{*}{$\begin{array}{l}\text { Passageiros trans- } \\
\text { portados por hora }\end{array}$} \\
\hline Saída & Chegada & Usuários & $\%$ & Usuários & $\%$ & & \\
\hline 07:00 & 08:00 & 78 & $87 \%$ & 2 & $100 \%$ & 15 & 312 \\
\hline 09:00 & $10: 00$ & 14 & $88 \%$ & 10 & $60 \%$ & 30 & 28 \\
\hline 11:00 & $12: 00$ & 4 & $100 \%$ & 15 & $93 \%$ & 20 & 12 \\
\hline 12:00 & $13: 00$ & 4 & $100 \%$ & 15 & $93 \%$ & 15 & 16 \\
\hline 13:00 & $14: 00$ & 43 & $88 \%$ & 28 & $93 \%$ & 20 & 129 \\
\hline 15:00 & $16: 00$ & 23 & $78 \%$ & 20 & $100 \%$ & 30 & 46 \\
\hline 18:00 & 19:00 & 29 & $100 \%$ & 26 & $100 \%$ & 15 & 116 \\
\hline 19:00 & 20:00 & 66 & $85 \%$ & 15 & $100 \%$ & 15 & 264 \\
\hline 20:00 & 21:00 & 50 & $90 \%$ & 15 & $95 \%$ & 15 & 200 \\
\hline
\end{tabular}


se fundamental planejar e buscar formas de melhorar o transporte público e qualificar o transporte fretado, sob pena de perda de segurança com a utilização de veículos velhos e sem manutenção, que muitas vezes são usados para desempenhar esse serviço. É importante lembrar que o CAA possui picos de entrada e saída de pessoas bem definidos e isso pode facilitar esse planejamento.

Também é importante ressaltar o caráter regional do CAA, que recebe estudantes de várias cidades e isso deve ser considerado no dimensionamento do estacionamento permanente da instituição, com vagas adequadas para vans e ônibus fretados e desenho compatível com as necessidade operacionais desses veículos.

Recomenda-se ainda, para trabalhos futuros, a realização de pesquisas semelhantes em outras IES da região para identificar se essa característica se repete, visando a elaboração de um banco de dados e a criação de uma metodologia de planejamento voltada para atender esses usuários que precisam se deslocar, às vezes, mais de 100 km diariamente para estudar. Por fim, e com base nesses estudos, recomenda-se ao MEC avaliar a criação de programas de transporte universitário escolar para apoiar a grande massa de alunos carentes, que demandam ensino superior nas instituições públicas que atendem a uma clientela regional.

\section{AGRADECIMENTOS}

Os autores agradecem à Elânia Melo e aos alunos da disciplina Tópicos Especiais em Transportes 3 da graduação em Engenharia Civil do CAA pela ajuda, colaboração e dedicação na pesquisa de campo e sem a qual este trabalho seria impossível. E à Rede $\mathrm{PGV}$ e ao $\mathrm{CNPq}$ pelo apoio financeiro e incentivo na elaboração dessa pesquisa.

\section{REFERÊNCIAS}

ANDRADE, M. O.; MEIRA, L. H.; e MAIA, M. L. A. Advantages and difficulties of public transportation by charter as an enabler of university education. Anais do 13th World Conference in Transportation Research. Rio de Janeiro - RJ, 2013.

BERTAZZO, A. B. S.; GALARRAGA, J.; HERZ, M.; e JACQUES, M. A. P. Estabelecimentos de ensino, polos geradores de viagens orientados à qualidade de vida e ambiental: modelos e taxas de geração de viagens. Capítulo 10. Rede Ibero-Americana de Estudo em Polos Geradores. Editora Interciência, p 289-327, 2010. ISBN: 978-85-7193-305-7.

BRASIL. Mapa de expansão das universidades federais. Programa de Restruturação e Expansão das Universidades Federais REUNI. Ministério da Educação. Brasília - DF, 2013. Disponível em <http://painel.mec.gov.br/academico/mapaSupProf/acao/S>. Acessado em outubro de 2013.

CET. Polos geradores de tráfego. Boletim Técnico nº 32. Companhia de Engenharia de Tráfego - CET. São Paulo - SP, 1983.

CONDEPE-FIDEM. Cadernos municipais - Base de Dados do Estado (BDE). Agência Estadual de Planejamento e Pesquisas de Pernambuco - CONDEPE-FIDEM, Recife - PE, 2011a. Disponível em <www.bde.pe.gov.br/estruturacaogeral/filtroCadernoEsta tistico.aspx>. Acessado em julho de 2011.

CONDEPE-FIDEM. PIB municipal de Pernambuco. Agência Estadual de Planejamento e Pesquisas de Pernambuco - CONDEPEFIDEM, Recife - PE, 2011b. Disponível em <www2.condepefid
em.pe.gov.br/c/portal/layout?p_1_id=PUB.1557.63>. Acessado em julho de 2011.

HERZ, M.; GALARRAGA, J.; e PASTOR, G. Centros universitários como polos geradores de viagens. Anais do XXI Congresso de Pesquisa e Ensino em Transportes - ANPET. Rio de Janeiro RJ, 2007.

HERZ, M.; GALARRAGA, J.; e Pastor, G. Características de generación y distribución modal de viajes en centros educativos universitarios. Anais do XV Congreso Latinoamericano de Transporte Público y Urbano - CLATPU. Buenos Aires, Argentina, 2009.

IBGE. População residente, total, urbana total e urbana na sede municipal, em números absolutos e relativos, com indicação da área total e densidade demográfica, segundo os municípios - Pernambuco - 2010. Instituto Brasileiro de Geografia e Estatística IBGE, Brasília - DF, 2010. Disponível em $<$ www.ibge.gov.br/home/estatistica/populacao/censo2010/tabelas _pdf/Pernambuco.pdf>. Acessado em julho de 2011.

MAIA, M. L. A.; MORAES, E. B. A.; SINAY, M. C. F.; CARVALHO, S. D.; CUNHA, R. F. F.; e PORTUGAL, L. S. Licenciamento de polos geradores de viagens. Polos geradores de viagens orientados a qualidade de vida e ambiental: modelos e taxas de geração de viagens. Capítulo 2. Rede Ibero-Americana de Estudo em Polos Geradores, Editora Interciência, p. 47, 2010. ISBN: 978-85-7193-305-7.

MARTINS, C. B. A formação de um Sistema de Ensino Superior de Massa. Revista Brasileira de Ciências Sociais, Vol. 17, ${ }^{\circ}$. 48, 2002. Disponível em <www.scielo.br/pdf/rbcsoc/v17n48/13956. pdf $>$. Acessado em julho de 2011. DOI: 10.1590/S010269092002000100012.

NUNES, J. L. Estudo da demanda por estacionamento em Instituições de Ensino Superior. Dissertação de Mestrado, 167p. Universidade de Brasília - UnB, Brasília - DF, 2005.

SOUZA, S. C. F. Modelos de geração de viagens para Instituições de Ensino Superior. Dissertação de Mestrado, 184p. Universidade de Brasília - UnB, Brasília - DF, 2007.

TECTRAN. Estudos de circulação e estacionamento. Técnicos em Transportes Ltda. Unidade Arcos - PUC Minas. Belo Horizonte - MG, 2003a.

TECTRAN. Relatório de impacto na circulação da Escola de Engenharia e da Faculdade de Ciências Econômicas da Universidade Federal de Minas Gerais. Técnicos em Transportes Ltda., 2003b.

TECTRAN. Relatório de impacto na circulação da Faculdade Estácio de Sá de Belo Horizonte - Campus Prado, Técnicos em Transportes Ltda., 2004. 